\title{
Diagnóstico pós-morte de Aelurostrongylus abstrusus e caracterização morfométrica de ovos e mórulas por meio de histologia e impressão de tecido
}

\author{
Diagnostic post-mortem of Aelurostrongylus abstrusus and the morphometric \\ characterization of the eggs and the morule by histology and tissue imprint
}

\author{
Alessandra Scofield ${ }^{1}$ Renata Cunha Madureira ${ }^{1}$ \\ Carlo José Freire de Oliveira² ${ }^{2}$ Daniel da Silva Guedes Junior ${ }^{3}$ \\ Cleber Oliveira Soares ${ }^{4}$ Adivaldo Henrique da Fonseca ${ }^{5}$
}

\begin{abstract}
- NOTA -
\section{RESUMO}

Os objetivos deste trabalho foram diagnosticar Aelurostrongylus abstrusus por meio das técnicas de histologia e impressão de tecido pulmonar de gato doméstico e realizar a caracterização morfométrica de ovos e mórulas desse nematódeo. Pela histologia, os ovos $(n=100)$ mediram, em média, 83,4 $x$ $65,5 \mu \mathrm{m}$, indice morfométrico (IM) 0,8 e as mórulas $(n=100)$ mediram, em média, 45,4 x 31,8 $\mu$ m, IM 0,7. Pela impressão de

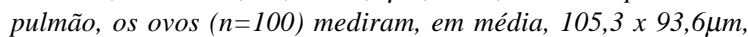

When observed in histological sections, the mean size of the eggs $(n=100)$ was $83,4 \times 65,5 \mu m$, morphometric index $(M I)$ 0,8 , and the mean size of the morule $(n=100)$ was $45,4 x$ 31,8 um, MI 0,7. When observed in the lung tissue imprint, the mean size of the eggs $(n=100)$ was 105,3 $\times 93,6 \mu \mathrm{m}$, MI 0,9 and the mean size of the morule $(n=100)$ was $43,1 \times 36,5 \mathrm{~mm}$, MI 0,8. The lung tissue imprint employed allowed the observation of the same parasitic forms visualized in histological sections. The results suggest the viability of using this technique for the pós-morte diagnostic of A. abstrusus.
\end{abstract} IM 0,9, e as mórulas $(n=100)$ mediram, em média, 43,1 $x$ 36,5 4 m, IM 0,8. A utilização da técnica de impressão de tecido permitiu a observação das mesmas formas parasitárias visualizadas histologicamente. Os resultados sugerem a viabilidade da utilização dessa técnica no diagnóstico pós-morte de A. abstrusus.

Palavras-chave: verme pulmonar, histologia, impressão de tecido, morfometria.

\section{ABSTRACT}

The aim of this work was the diagnose of Aelurostrongylus abstrusus using histological techniques and lung tissue imprint, performing also morfometric characterization of the eggs and the morule of this nematode.
Key words: lung worm, histology, imprint, morphometry.

Aelurostrongylus abstrusus é um nematódeo de distribuição mundial (HAMILTON \& MCCAW, 1968; LANE \& KOCAN, 1983; SOULSBY, 1987; WILLARD et al., 1988) que parasita pequenas ramificações de artérias pulmonares, alvéolos, dutos alveolares e bronquíolos de gatos domésticos (MILLER et al., 1984; RIBEIRO \& LIMA, 2001; TÜZER et al., 2002) e felídeos silvestres (WEST et

${ }^{1}$ Curso de Pós-graduação em Ciências Veterinárias, Universidade Federal Rural do Rio de Janeiro (UFRRJ), Br 465, Km 7,5, 23851-970, Seropédica, RJ, Brasil. E-mail: lecascofield@ hotmail.com. Autor para correspondência.

${ }^{2}$ Curso de Pós-graduação em Imunologia Básica e Aplicada, Faculdade de Medicina de Ribeirão Preto Universidade São Paulo (USP), Ribeirão Preto, SP, Brasil.

${ }^{3}$ Curso de Pós-graduação em Medicina Veterinária, UFRRJ, Seropédica, RJ, Brasil.

${ }^{4}$ Pesquisador do Centro Nacional de Pesquisa de Gado de Corte (CNPGC), Empresa Brasileira de Pesquisa Agropecuária (EMBRAPA), Campo Grande, MS, Brasil.

${ }^{5}$ Departamento de Epidemiologia e Saúde Pública, Laboratório de Doenças Parasitárias, UFRRJ, Seropédica, RJ, Brasil. 
al., 1977; CASTRO et al., 1999; BJORK et al., 2000). Os sinais clínicos e lesões de aelurostrongilose dependem da quantidade de parasitos envolvidos e da resposta dos felídeos às formas parasitárias adultas, larvas e ovos (SCOTT, 1973). As infecções severas freqüentemente acarretam pneumonia, efusão pleural, piotórax, anorexia, diarréia e morte súbita, devido à postura simultânea de grande número de ovos no parênquima pulmonar (MILLER et al., 1984; SOULSBY, 1987).

O ciclo de vida de A. abstrusus é complexo e envolve moluscos terrestres e aquáticos, como hospedeiros intermediários, e répteis, anfíbios, aves e pequenos mamíferos, como hospedeiros paratênicos. A infecção em gatos é resultante da ingestão de um desses hospedeiros e as larvas infectantes de terceiro estádio penetram na mucosa do sistema digestivo do hospedeiro definitivo e chega aos pulmões pelo sistema linfático, onde desenvolvem-se até as formas adultas. A oviposição e o desenvolvimento das larvas de primeiro estádio ocorrem no parênquima pulmonar. Ovos e larvas são posteriormente deglutidos e eliminados juntamente com as fezes. No meio ambiente, as larvas livres sobrevivem por até duas semanas e, ao serem ingeridas ou penetrarem nos hospedeiros intermediários, desenvolvem-se em larvas de terceiro estádio infectantes (HAMILTON \& MCCAW, 1968; SOULSBY, 1987; RIBEIRO \& LIMA, 2001).

A determinação da prevalência de aelurostrongilose, nos hospitais veterinários tem sido dificultada, devido à ausência de sinais clínicos e à falta de diagnóstico (SCOTT, 1973). O diagnóstico tem sido realizado através de exames coprológicos (CASTRO et al., 1999; SCHUSTER, R. et al., 1999; TÜZER et al., 2002), lavado traqueal (BARRS et al., 1999), histologia (WILLARD et al., 1988) e radiografia de pulmão (LOSONSKY et al., 1983; WILLARD et al., 1988; BARRS et al., 1999).

O presente trabalho teve como objetivos realizar o diagnóstico pós-morte de A. abstrusus em um gato doméstico, por meio das técnicas de histologia e impressão de tecido pulmonar, e caracterizar morfometricamente ovos e mórulas desse nematódeo.

Em junho de 1998, um gato doméstico fêmea, de aproximadamente 12 anos, veio a óbito em conseqüência de complicações respiratórias. À necropsia, fragmentos de diferentes órgãos foram coletados para serem processados segundo as técnicas de histologia e impressão de tecido. As amostras destinadas à histologia foram fixadas em formol a $10 \%$ e processadas pelos métodos rotineiros, incluídas em parafina, cortadas na espessura de $5 \mu \mathrm{m}$ e coradas com hematoxilina-eosina (HE), para posterior exame em microscópio óptico. Para a técnica de impressão de tecido, fragmentos de tecido a fresco foram pressionados sobre lâminas, por aproximadamente três segundos, favorecendo a manutenção da sua impressão. Após a confecção das lâminas, elas foram fixadas em álcool metílico absoluto e coradas durante 30 minutos com Giemsa diluído em tampão fosfatado pH 6,8, para posterior exame em microscópio óptico.

Procedeu-se a caracterização morfométrica de um parasito pulmonar mensurando 100 formas de ovos e 100 mórulas, nos cortes histológicos, e 100 formas de ovos e 100 mórulas, nas impressões de pulmão, por análise em um microscópio fotônico (Leitz Wetzalar - Dialux 20 EB), sob objetiva de 40X acoplada a uma ocular micrométrica (Wild-pZo) com aumento de 15X. Foram avaliados os parâmetros relativos ao diâmetro menor $(\mathrm{dm})$, ao diâmetro maior (DM) e ao índice morfométrico $(\mathrm{IM}=\mathrm{dm} / \mathrm{DM})$ das formas parasitárias analisadas.

Nos cortes histológicos de pulmão e nas lâminas de impressão pulmonar, foram observados ovos (Figuras 1 e 2 A-C) e larvas em diferentes fases de desenvolvimento de A. abstrusus (Figuras 1 e 2 BD). Pela análise histológica os ovos $(\mathrm{n}=100)$ mediram $83,4 \pm 12,9 \times 65,5 \pm 9,1 \mu \mathrm{m}$, IM 0,8 $\pm 0,1$, e as mórulas $(\mathrm{n}=100)$ mediram $45,4 \pm 6,3 \times 31,8 \pm 4,7$, IM 0,7 \pm 0,1 . Pela análise de impressões de pulmão, os ovos $(\mathrm{n}=100)$ mediram 105,3 $\pm 11,3 \times 93,6 \pm 12,7$, IM 0,9 $\pm 0,1$, e as mórulas $(\mathrm{n}=100)$ mediram $43,1 \pm 10,6 \mathrm{x}$ $36,5 \pm 9,9 \mu \mathrm{m}$, IM $0,8 \pm 0,1$.

Raros são os relatos de diagnóstico pósmorte de aerulostrongilose, sendo a análise histológica a técnica empregada nesses casos. Em um estudo de prevalência de parasitos respiratórios e avaliação de diferentes técnicas de diagnóstico,

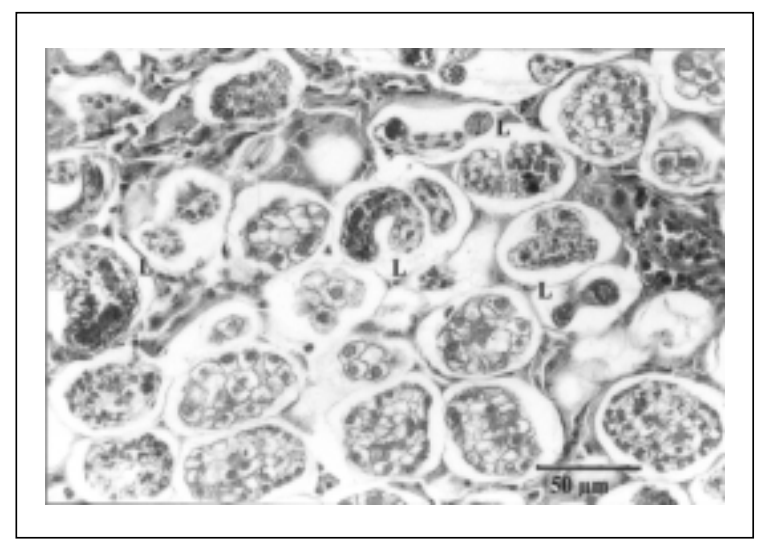

Figura 1 - Formas evolutivas de Aelurostrongylus abstrusus em histologia de pulmão de gato doméstico: ovos e larvas em formação (L) (HE, objetiva 40X, ocular 10X).

Ciência Rural, v.35, n.4, jul-ago, 2005. 


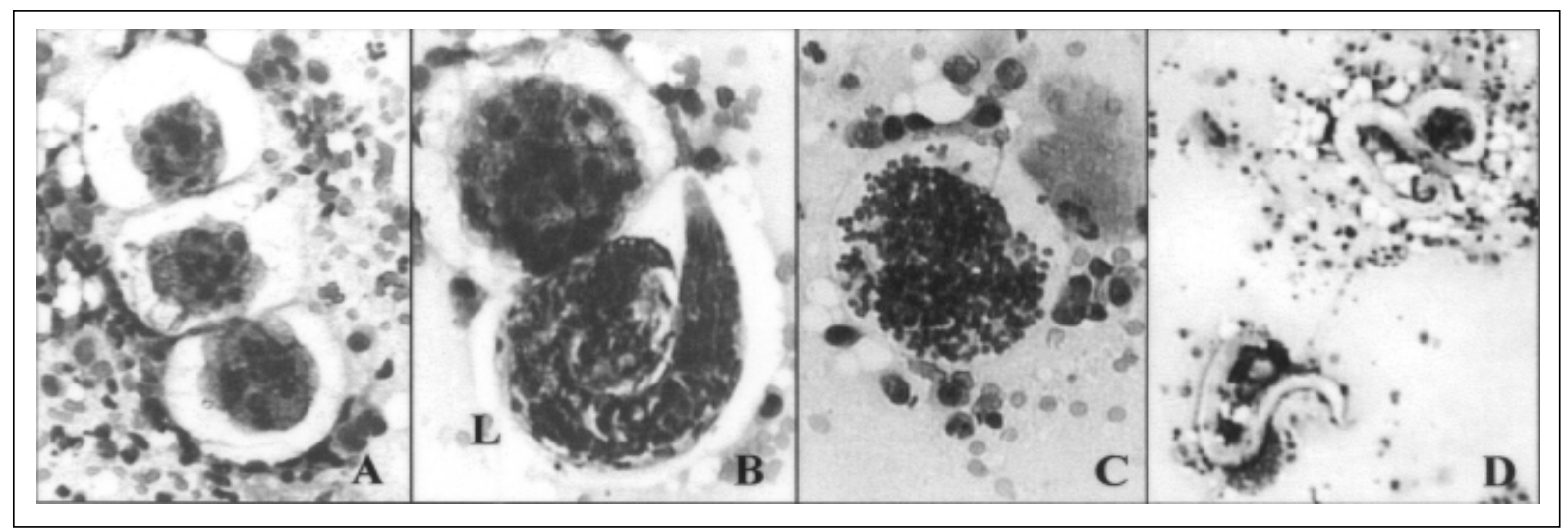

Figura 2 - Formas evolutivas de Aelurostrongylus abstrusus em impressão de tecido pulmonar de gato doméstico. A. Ovos em fase de mórula (Giemsa, objetiva 20X, ocular 10X); B. Ovo e larva em formação (L)(Giemsa, objetiva 40X, ocular 10X); C. Ovo em fase de formação de larva (Giemsa, objetiva 40X, ocular 10X); D. Larvas (Giemsa, objetiva 10X, ocular 10X).

WILLARD et al. (1988) examinaram 108 gatos domésticos eutanizados, diagnosticando $\boldsymbol{A}$. abstrusus em vinte deles (18,5\%) pelo exame coprológico, necropsia ou exame histológico. Dezoito desses vinte animais apresentaram larvas de primeiro estádio, detectadas ao exame coprológico utilizando a técnica de Baerman. Nove destes gatos também apresentaram formas adultas no pulmão, observadas ao exame histológico. Apenas dois animais com aelurostrongilose (10\%) foram diagnosticados pela detecção dos parasitos somente no exame histológico de pulmão.

No presente trabalho, diferentes formas evolutivas de $\boldsymbol{A}$. abstrusus foram observadas tanto por exame histológico, quanto pela técnica de impressão de tecido. Com isso, os autores sugerem a viabilidade da utilização da técnica de impressão de tecido no diagnóstico pós-morte de A. abstrusus, uma vez que ela é rápida, de baixo custo e de fácil execução. No entanto, ressalta-se a importância da realização de estudos com um número maior de casos de aelurostrongilose felina, para avaliação da eficiência dessa técnica.

\section{AGRADECIMENTOS}

Nossos agradecimentos ao CNPq, CAPES e FAPERJ pelo apoio financeiro.

\section{REFERÊNCIAS}

BARRS, V.R. et al. Concurrent Aelurostrongylus abstrusus infection and salmonellosis in a kitten. Australian Veterinary Journal, v.77, n.4, p.229-232, 1999.

BJORK, K.E. et al. Parasites and parasite stages of freeranging wild lions (Panthera leo) of Northern Tanzania.
Journal of Zoo and Wildlife Medicine, v.31, n.1, p.56-61, 2000 .

CASTRO, J.M. Ocorrência de parasitos em felídeos de zoológicos do Estado de Minas Gerais - Brasil. In: SEMINÁRIO BRASILEIRO DE PARASITOLOGIA VETERINÁRIA, 11., 1999, Salvador-BA. Anais... Ilhéus : Universidade Estadual de Santa Cruz, 1999. 250p. p. 181 .

HAMILTON, J.M.; MCCAW, A.W. The output of first stage larvae by cats infested with Aelurostrongylus abstrusus. Journal of Helminthology, v.XLII, n.3/ 4, p.295-298, 1968.

LANE, J.R.; KOCAN, A.A. Hepatozoon sp infection in bobcats. Journal of American Veterinary Medical Association, v.183, n.11, p.1323-1324, 1983.

LOSONSKY, J.M. et al. Radiographic evaluation of pulmonary abnormalities after Aelurostrongylus abstrusus inoculation in cats. American Journal of Veterinary Research, v.44, p.478-482, 1983.

MILLER, B.H. et al. Pleural effusion as a sequela to aelurostrongylosis in a cat. Journal of American Veterinary Medical Association, v.185, n.5, p.556-557, 1984.

RIBEIRO, V.M.; LIMA, W.S. Larval production of cats infected and re-infected with Aelurostrongylus abstrusus (Nematoda: Protostrongylidae). Revue Médicine Veterinarie, v.152, n.11, p.815-820, 2001.

SCHUSTER, R. et al. Opisthorchis felineus, Ancylostoma tubaeforme und Aelurostrongylus abstrusus 3 selten diagnostizierte parasiten bei einer einheimischen hauskatze. Kleintierpraxis, v.2, p.73-148, 1999.

SCOTT, D.W. Current knowledge of aelurostrongylosis in the cat. Cornell Veterinary, v.63, p.483-500, 1973.

SOUSLBY, E.J.L. Parasitología y enfermedades parasitarias en los animales domésticos. México, London: Bailliére, Tindall and Cassell, 1987. 824p. 
TÜZER, E. et al. A case of Aelurostrongylus abstrusus infection in a cat in Istanbul, Turkey and its treatment with moxidectin and levamisole. Turk Journal Veterinary Animal Science, v.26, p.411-414, 2002.

WILLARD, M.D. Diagnosis of Aelurostrongylus abstrusus and Dirofilaria immitis infectios in cats from a humane shelter. Journal of American Veterinary Medical Association, v.192, n.7, p.913916,1988 .

WEST, B. et al. Aelurostrongylus abstrusus infection in the cheetah. Journal of Helminthology, v.51, n.3, p. $210-1,1977$ 